Archive for

Organic Chemistry

Arkivoc 2018, part vii , 0-0

\title{
The carbamate esters as organocatalysts in asymmetric Michael addition reactions in aqueous media: when pyrrolidine backbone surpasses 1,2- diaminocyclohexane
}

\author{
Anirban Mondal and Kartick C. Bhowmick ${ }^{*}$ \\ Division of Organic Synthesis, Department of Chemistry, Visva-Bharati (A Central University); Bolpur, West \\ Bengal-731 235, India \\ Email: kartickc.bhowmick@visva-bharati.ac.in
}

Received 07-16-2018

Accepted 10-15-2018

Published on line 10-29-2018

\section{Abstract}

A pyrrolidine ring containing carbamate ester, pyrrolidine-2-ylmethyl-carbamic acid isobutyl ester has been synthesized. The newly developed pyrrolidine ring containing carbamate ester surpassed 1,2diaminocyclohexane derived carbamate ester in asymmetric Michael addition reactions in aqueous media providing Michael products with yields (up to 97\%), syn diastereoselectivities (up to 97\%) and enantioselectivities (up to 94\%).

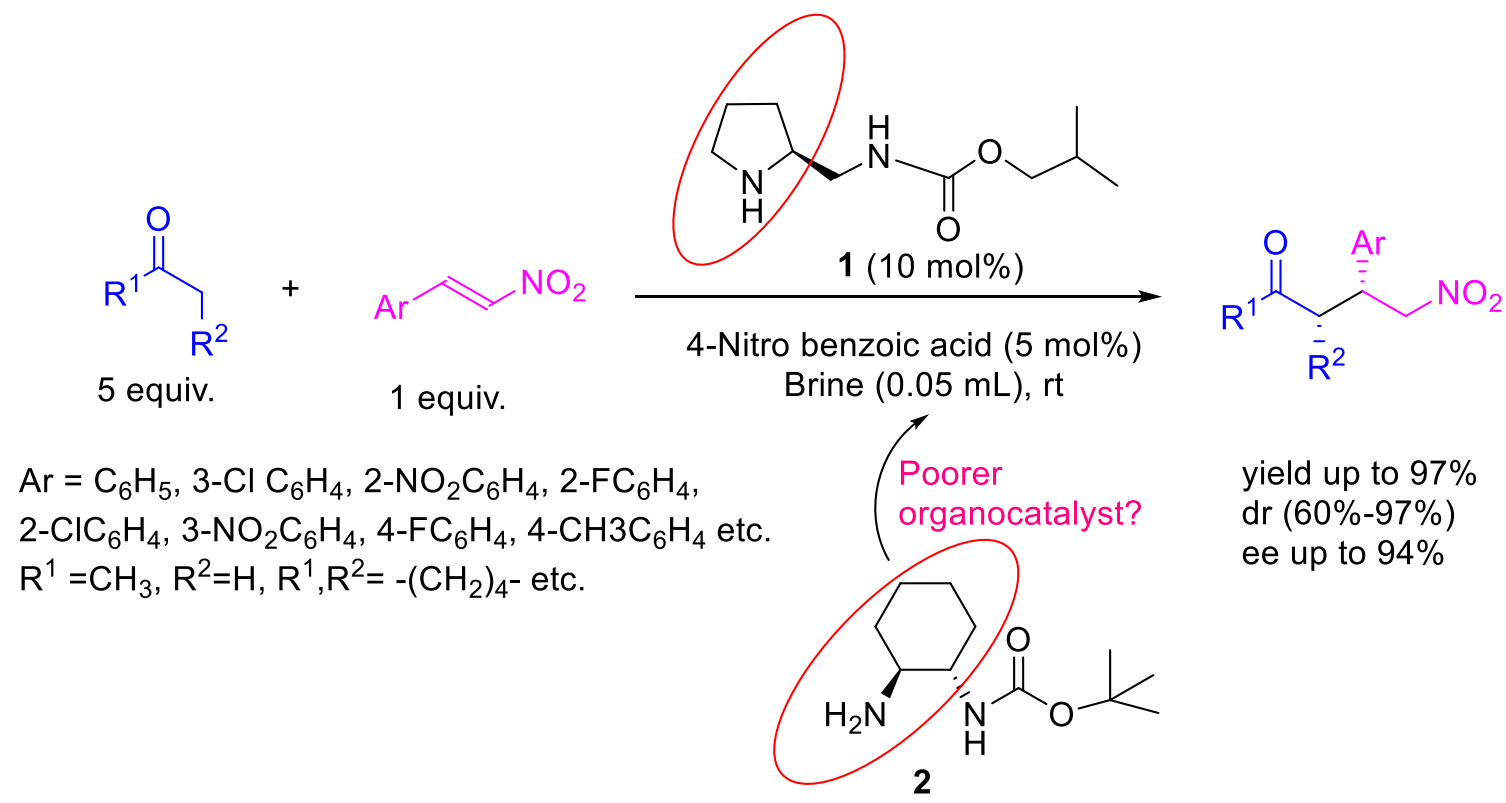

Keywords: Asymmetric organocatalysis, Michael reaction, pyrrolidine-based carbamate ester, aqueous media 


\section{Introduction}

Asymmetric $\mathrm{C}-\mathrm{C}$ bond-forming reactions provide a plethora of opportunities towards the synthesis of diverse chiral compounds of significant applications in wide array of fields. ${ }^{1-3}$ It is to note that catalytic asymmetric Michael addition reaction or 1,4-conjugate addition reaction is one of the most important and versatile $\mathrm{C}-\mathrm{C}$ bond forming reaction apart from aldol reactions, Diels-Alder reactions, Mannich reactions etc. ${ }^{4-9}$ Multiple stereogenic centers can be generated in a single step process by this conjugate addition reaction.

Chiral metal complex catalysis and biocatalysis have been the main focus of research in the Michael addition reactions along with other classical C-C bond-forming transformations until the beginning of $21^{\text {st }}$ century. ${ }^{10-21}$ Barbas group and MacMillan group independently initiated a new asymmetric catalysis which was judiciously termed as 'organocatalysis' by MacMillan. The aforesaid groups exploited the organocatalysis in asymmetric intermolecular aldol reactions and asymmetric Diels-Alder reactions respectively. ${ }^{19-20}$ In addition to these reports, Hanessian and group unveiled the first asymmetric organocatalytic intermolecular Michael addition reaction in organic media. ${ }^{21}$ Since then, there have been several reports on asymmetric organocatalytic Michael addition reactions and other classical C-C bond-forming reactions in organic media.

Organocatalysis employing aqueous conditions is a very common practice. ${ }^{22-26}$ However, surprisingly very few reports were found for asymmetric organocatalytic Michael reactions in aqueous media. ${ }^{27-51}$ Use of water as solvent may be beneficial with multiple advantages in the 1, 4-conjugate addition reactions. It was evident that water not only accelerated the reaction rates but also it could enhance the stereoselectivity. ${ }^{52}$ Various derivatives of proline showed significant catalytic activity as organocatalyst in asymmetric Michael addition reactions in aqueous and semi-aqueous media, and remarkably high enantioselective Michael products were resulted under this condition. ${ }^{53-54}$

Even though there have been many proline derived organocatalysts but a proline-based carbamate type organocatalyst is not known in the literature. However, Chincilla and group developed a 1, 2-diamino cyclohexane-based carbamate ester $\mathbf{2}$ for its application in Michael addition reaction between arylketones and acetone to nitroalkenes in organic media. ${ }^{55}$ The said catalyst $\mathbf{2}$ unfortunately provided very poor yield (53\%) and enantioselectivity (60\% ee) for the Michael reaction between acetophenone and $\beta$-nitrostyrene in water media. Even in the hazardous organic solvent such as chloroform, the catalyst $\mathbf{2}$ afforded highest 93\% enantioselectivity. Moreover, 1, 2-diamino cyclohexane-based carbamate ester $\mathbf{2}$ catalyzed $\alpha, \alpha$-disubstituted aldehydes and maleimides as Michael donor and acceptor respectively to furnish products with only $32 \%$ ee in water media. ${ }^{56}$ Notably, in presence of the same catalyst $\mathbf{2}$ for similar substrates, the enantioselectivity of Michael products reached to $94 \%$ in deep eutectic solvent. ${ }^{57}$ All these results indicate that the $1,2-$ diaminocyclohexane backbone in the carbamate type structure is somehow incapable of imparting good level of stereoselectivity in pure water media.

We then argued whether a pyrrolidine ring containing carbamate ester could be a better choice? Perhaps a pyrrolidine moiety in the carbamate type organocatalyst could be arguably an interesting choice for Michael reactions in aqueous media. In this context, a carbamate type organocatalyst, pyrrolidine-2-ylmethyl-carbamic acid isobutyl ester 1 has been synthesized starting from inexpensive and commercially available reagents such as isobutyl chloroformate $\mathbf{4}$ and 2-aminomethylpyrrolidine-1-carboxylic acid tert-butyl ester $\mathbf{3}$. Herein, we report the detailed study of a proline-derived carbamate ester organocatalyst $\mathbf{1}$ in Michael addition reactions in eco-friendly solvent like brine without any organic co-solvent. 


\section{Results and Discussion}

Carbamate ester 1 has been synthesized from commercially available N-Boc protected 2-amino methylpyrrolidine $\mathbf{3}$ and isobutyl chloroformate $\mathbf{4}$ following a very simple reaction sequence stated in Scheme 1. Initially, the N-Boc protected 2-amino methylpyrrolidine $\mathbf{3}$ was coupled with commercially available isobutyl chloroformate 4 to obtain the N-Boc protected compound $\mathbf{5}$, which upon trifluoro acetic acid treatment provided the desired catalyst 1 with $95 \%$ yield.

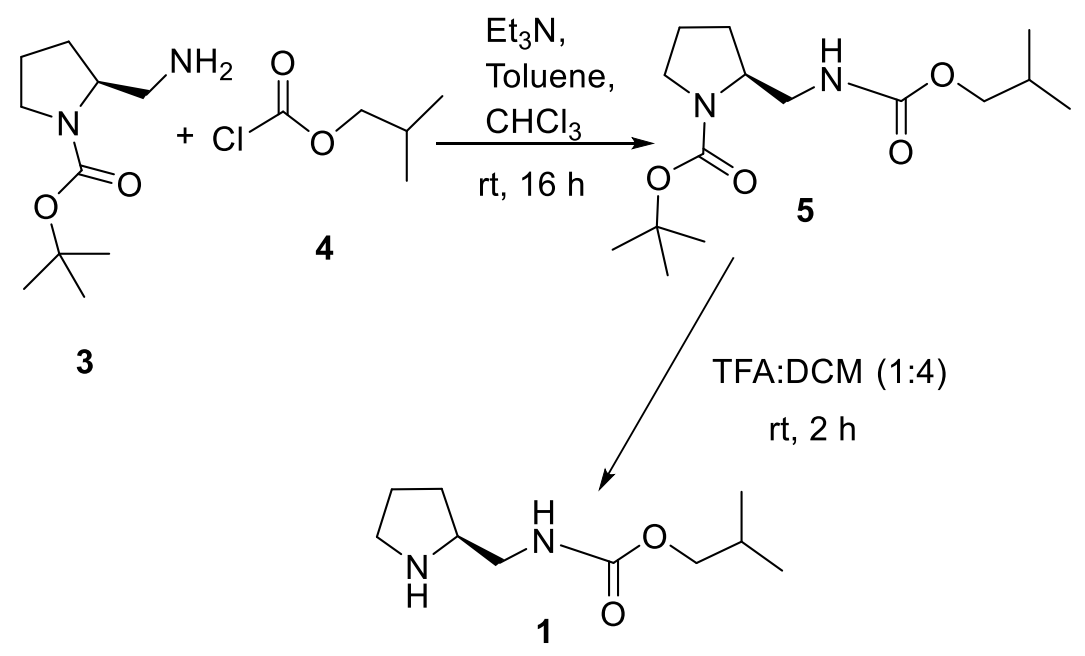

Scheme 1. Preparation of the catalyst 1.

The newly synthesized pyrrolidine carbamate ester 1 was then employed as catalyst in asymmetric Michael addition reaction of cyclohexanone to $\beta$-nitro styrene separately in aqueous and organic media to observe the catalytic activity of that organocatalysts. Frequently used organic solvents like toluene, chloroform, dichloromethane furnished the Michael adducts with only 46-54\% ee (entry 1-3, Table 1). These results indicate that catalyst $\mathbf{1}$ is inferior to catalyst $\mathbf{2}$ in organic media. Apart from the organic solvents, we were very curious to observe any positive effect of water as sole reaction medium when the catalyst is 1 . Indeed, the organocatalyst 1 afforded the Michael product with an increased diastereoselectivity (91\% de) and enantioselectivity $(80 \%$ ee) in pure water media (entry 4 , Table 1$)$. A similar experiment was also performed in $0.05 \mathrm{ml}$ of brine for the same Michael reaction. Interestingly, the catalyst 1 was found to be more efficient in brine media with an improved stereoselectivity ( $91 \%$ de, $86 \%$ ee) (entry 7 , Table 1 ). Furthermore, it was also observed that the same Michael reaction resulted inferior yield (90\%) and stereoselectivity in neat condition ( $88 \%$ de, $82 \%$ ee) (entry 5, Table 1). Thus, the synchronization of brine as solvent with organocatalyst 1 in providing the optimum result has been observed in this particular reaction. To further optimize the reaction condition, the additive quantity was then varied in brine. A higher additive loading (10 mol\%) was found to be detrimental to both diastereoselectivity $(90 \%$ de) and enantioselectivity $(81 \%$ ee) in brine media (entry 6 , Table 1). 
Table 1. Screening of solvents and additive loading

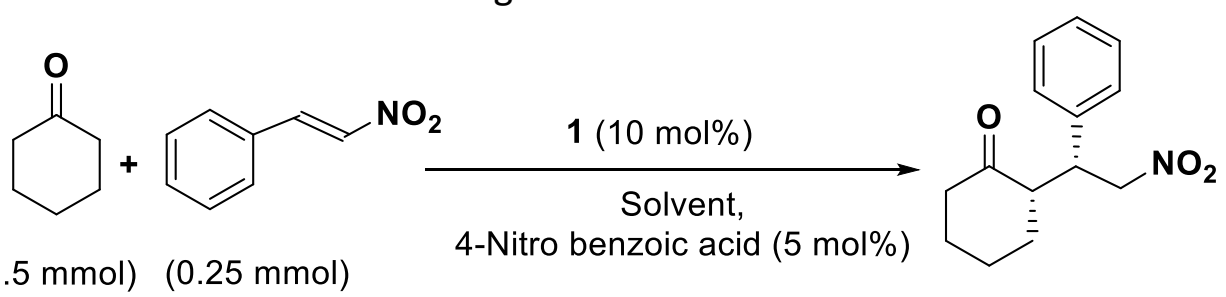

\begin{tabular}{ccccc}
\hline Entry & Solvent & yield $^{\mathbf{a}}$ & \%de $^{\mathbf{b}}$ & \%ee $^{\mathbf{c}}$ \\
\hline 1 & Toluene & 91 & 76 & 46 \\
2 & $\mathrm{CH}_{2} \mathrm{Cl}_{2}$ & 97 & 79 & 48 \\
3 & $\mathrm{CHCl}_{3}$ & 81 & 82 & 54 \\
4 & $\mathrm{H}_{2} \mathrm{O}$ & 93 & 91 & 80 \\
5 & - & 90 & 88 & 82 \\
$6^{\text {d }}$ & Brine & 93 & 90 & 81 \\
$\mathbf{7}$ & Brine & $\mathbf{9 3}$ & $\mathbf{9 1}$ & $\mathbf{8 6}$ \\
\hline
\end{tabular}

${ }^{a}$ Yield after purification by column chromatography. ${ }^{b}$ Diastereomer ratios (anti/syn) were determined by ${ }^{1} \mathrm{H}$ NMR spectrum of the crude product mixture. ${ }^{c}$ Enantiomeric excess were determined by the chiral HPLC study of the syn isomer. ${ }^{\mathrm{d}} 10$ mol\% additive was used.

Once brine was found to be the best solvent, we next checked the volume of brine for the optimization of yield and stereoselectivity in the present asymmetric Michael addition reaction. Different results were obtained by altering the volume of brine. As we have already observed when the brine volume was taken 0.05 $\mathrm{ml}$ with 10 mol\% of catalyst 1, 93\% yield and $86 \%$ ee of Michael product was obtained (entry 7, Table 1). Increasing or decreasing the brine volume otherwise affected both the yields and stereoselectivities (entry 1 \& 2, Table 2). Subsequently, interesting results were obtained during the optimization studies with different catalyst loading. It was noticed that the $10 \mathrm{~mol} \%$ catalyst loading afforded best yield as well as stereoselectivity in the Michael reaction (entry 7, Table 1). A lower catalyst loading (5 mol\%) furnished only $80 \%$ ee (entry 3, Table 2), while a higher loading (20 mol\%) increased the chemical yield to $98 \%$, however, the enatioselectivity was only $68 \%$ for the Michael product (entry 4, Table 2). Next, we examined different ratio of nitrostyrene and cyclohexanone to see their effect. Very interestingly, an improved enantioselectivity (94\% ee) was obtained when 5 equiv. of cyclohexanone was taken with respect to nitrostyrene in brine medium (entry 5, Table 2). Further lower (1:3) ketone/nitrostyrene ratio furnished only 59\% ee in brine media (entry 6, Table 2).

Acid additive often can significantly influence the outcome of both yield and enantioslectivity in organocatalyzed asymmetric Michael addition reaction. ${ }^{58}$ In order to see such influence, we examined various acid additives such as trifluoroacetic acid, benzoic acid, adipic acid, citric acid etc. apart from 4-nitrobenzoic acid in the Michael reaction in brine media. After the sincere additive screening, it was found that all the acid additives afforded inferior enantioselectivity compared to 4-nitro benzoic acid (Table 3). The same Michael reaction without any acid additive also furnished a lower enantioselectivity (79\%) (entry 2, Table 3). Notably, the aromatic acid additives with medium acidity showed better chemical reactivity providing higher yield of the Michael products compared to strong aliphatic acid additives (Table 3). At this moment no concrete explanation is available with us, even though it may be assumed that in the presence of strong acid additive, the catalyst 1 is probably getting deactivated during the reaction. 
Table 2 Screening of catalyst loading and volume of brine

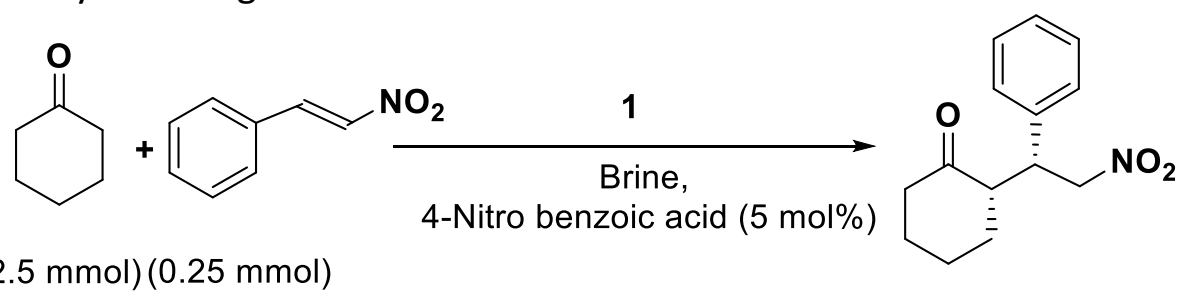

$(2.5 \mathrm{mmol})(0.25 \mathrm{mmol})$

\begin{tabular}{cccccc}
\hline Entry & Catalyst (mol\%) & Brine $(\mathbf{m L})$ & Yield (\%) $^{\mathbf{a}}$ & de (\%) & ee (\%) \\
\hline 1 & 10 & 0.1 & 20 & 99 & 82 \\
2 & 10 & 0.01 & 51 & 73 & 81 \\
3 & 5 & 0.05 & 27 & 77 & 80 \\
4 & 20 & 0.05 & 98 & 86 & 68 \\
$\mathbf{5}^{\mathbf{d}}$ & 10 & 0.05 & 92 & 94 & 94 \\
$6^{\mathrm{e}}$ & 10 & 0.05 & 85 & 93 & 59 \\
\hline
\end{tabular}

a Yield after purification by column chromatography. ${ }^{b}$ Diastereomer ratios (anti/syn) were determined by ${ }^{1} \mathrm{H}$ NMR spectrum of the crude product mixture. ${ }^{\mathrm{C}}$ Enantiomeric excess were determined by the chiral HPLC study of the syn isomer.

${ }^{d}$ Cyclohexanone $(1.25 \mathrm{mmol}), \beta$-nitro styrene $(0.25 \mathrm{mmol})$ were used. ${ }^{e}$ Cyclohexanone $(0.75 \mathrm{mmol}), \beta$-nitro styrene $(0.25 \mathrm{mmol})$ were used.

Table 3 Screening of acid additives

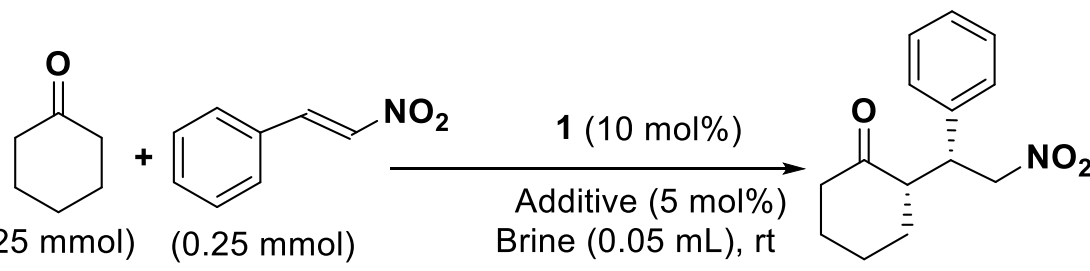

\begin{tabular}{ccccc}
\hline Entry & Additive (pk $\mathbf{a})$ & $\begin{array}{c}\text { Yield } \\
(\mathbf{\%})^{\mathbf{a}}\end{array}$ & de (\%) & ee (\%) \\
\hline $\mathbf{1}$ & 4-Nitro benzoic acid (3.41) & $\mathbf{9 2}$ & 94 & $\mathbf{9 4}$ \\
$\mathbf{2}$ & - & 95 & 95 & 79 \\
3 & 3,5-Dinitro benzoic acid (2.77) & 93 & 91 & 66 \\
4 & p-Anisic acid (4.47) & 85 & 94 & 70 \\
5 & Benzoic acid (4.2) & 99 & 94 & 73 \\
6 & Stearic acid (10.15) & 96 & 95 & 67 \\
7 & Abietic acid (4.64) & 93 & 94 & 75 \\
8 & Adipic acid (4.43) & 90 & 95 & 63 \\
9 & Citric acid (3.14) & 33 & 89 & 64 \\
10 & L-(+)-Tartaric acid (2.89) & 27 & 90 & 64 \\
11 & Trifluoro acetic acid (0.23) & 10 & 82 & 69 \\
12 & $p-T o l u e n e$ Sulphonic acid (-2.8) & 27 & 91 & 74 \\
13 & Picric acid (0.38) & 27 & 85 & 75 \\
\hline
\end{tabular}

a Yield after purification by column chromatography.

${ }^{\mathrm{b}}$ Diastereomer ratios (anti/syn) were determined by ${ }^{1} \mathrm{H}$ NMR spectrum of the crude product mixture.

${ }^{c}$ Enantiomeric excess were determined by the chiral HPLC study of the syn isomer. 
After getting the optimized reaction condition, we then examined the substrate scope. Studies with various electron donating and electron withdrawing group substituted nitroolefins and ketones were performed to check the catalytic activity of our synthesized organocatalyst 1 (Table 4). Except acetone as Michael donor, most of the substrates furnished good diastereo- and enantioselectivity in presence of the newly developed carbamate organocatalyst $\mathbf{1}$ in brine. The cyclohexanone as Michael donor and $\beta$ nitrostyrene as Michael acceptor were found to be best substrates in terms of chemical yield as well as stereoselectivity in presence of organocatalyst 1 in brine (entry 1, Table 4). Nitro group substitution at meta position of the phenyl ring also afforded similar results (entry 10, Table 4). Fluoro- and choloro- substitution furnished little lower but similar enantioselectivities (entry 2, 5, 6, 7, 9, Table 4). In general, cyclohexanone was found to be better compared to cyclopentanone and acetone as Michael donor. All the Michael reactions were found to complete between 3-6 days in brine in presence of this pyrrolidine ring containing carbamate organocatalyst 1.

Table 4. Enantioselective Michael addition reaction of ketones to nitroolefins

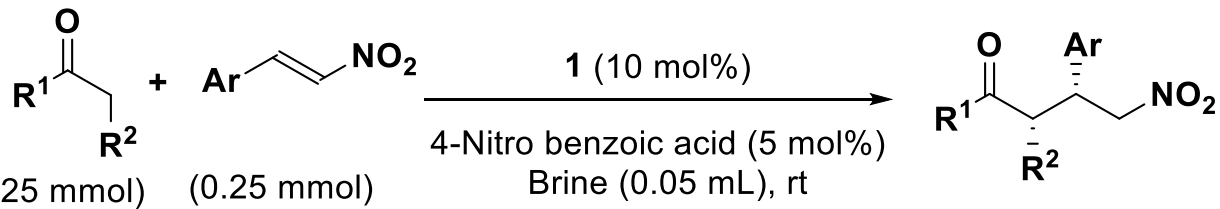

\begin{tabular}{|c|c|c|c|c|c|}
\hline Entry & Product & Time $^{d}$ & Yield (\%) ${ }^{a}$ & de $(\%)^{b}$ & ee $(\%)^{c}$ \\
\hline 1 & $\mathrm{Ar}=\mathrm{C}_{6} \mathrm{H}_{5}(6)$ & 3 & 92 & 94 & 94 \\
\hline 2 & $\mathrm{Ar}=3-\mathrm{Cl} \mathrm{C} \mathrm{CH}_{4}(7)$ & 5 & 97 & 80 & 85 \\
\hline 3 & $\mathrm{Ar}=2-\mathrm{NO}_{2} \mathrm{C}_{6} \mathrm{H}_{4}(8)$ & 6 & 90 & 90 & 85 \\
\hline 4 & $\mathrm{Ar}=4-\mathrm{CH}_{3} \mathrm{C}_{6} \mathrm{H}_{4}(9)$ & 4 & 96 & 90 & 83 \\
\hline 5 & $\mathrm{Ar}=3-\mathrm{FC}_{6} \mathrm{H}_{4}(10)$ & 4 & 95 & 82 & 86 \\
\hline 6 & $\mathrm{Ar}=2-\mathrm{FC}_{6} \mathrm{H}_{4}(\mathbf{1 1})$ & 3 & 85 & 97 & 74 \\
\hline 7 & $\mathrm{Ar}=2-\mathrm{Cl} \mathrm{C} \mathrm{CH}_{4}(\mathbf{1 2})$ & 5 & 88 & 95 & 87 \\
\hline 8 & $\mathrm{Ar}=4-\mathrm{CF}_{3} \mathrm{C}_{6} \mathrm{H}_{4}(13)$ & 4 & 83 & 95 & 87 \\
\hline 9 & $\mathrm{Ar}=4-\mathrm{FC}_{6} \mathrm{H}_{4}(\mathbf{1 4})$ & 4 & 92 & 93 & 87 \\
\hline 10 & $\mathrm{Ar}=3-\mathrm{NO}_{2} \mathrm{C}_{6} \mathrm{H}_{4}(15)$ & 5 & 95 & 72 & 93 \\
\hline 11 & $\mathrm{R}^{1}, \mathrm{R}^{2}=(\mathrm{CH} 2)_{3}(16)$ & 4 & 91 & 60 & 72 \\
\hline 12 & $\mathrm{R}^{1}=\mathrm{CH}_{3}, \mathrm{R}^{2}=\mathrm{H},(\mathbf{1 7})$ & 4 & 93 & -- & 33 \\
\hline
\end{tabular}

a Yields were determined by the column chromatography.

${ }^{b}$ Diastereomer ratios (anti/syn) were determined by ${ }^{1} \mathrm{H}$ NMR spectrum of the crude product mixture.

c Enantiomeric excess were determined by the chiral HPLC study of the syn isomer.

${ }^{\mathrm{d}}$ Days of reaction

A plausible transition state has been depicted for the Michael reaction in brine media in Figure 1. The figure 1 shows how water and acid additive may stabilize the proposed transition state through hydrogen bonding. The isobutyl moiety in the catalyst structure may shield the upper face of the double bond of nitrostyrenes favouring downface attack that results the desired stereochemical outcome in the reaction. 


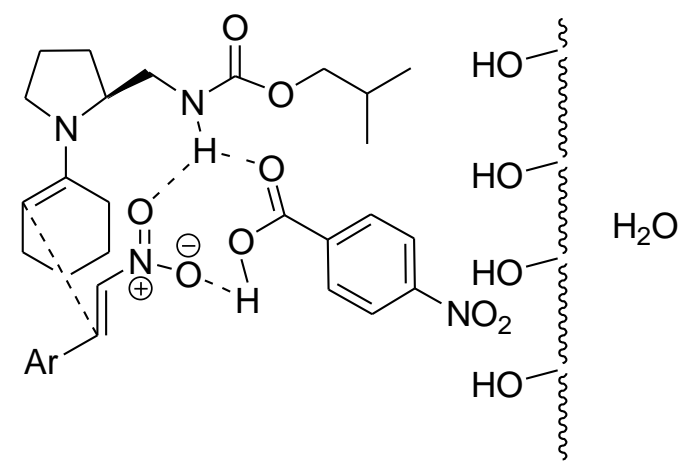

Figure 1. Proposed transition state in presence of catalyst 1.

\section{Conclusions}

In summary, we have successfully synthesized a new carbamate organocatalysts 1 following a simple two step reaction protocol starting from commercially available reagents with good overall yield and utilized the catalyst 1 in the asymmetric Michael addition reaction in brine media. The organocatalyst $\mathbf{1}$ is the first prolinebased carbamate organocatalyst which has been tested in asymmetric Michael addition reaction in an aqueous environment. Various substrates with different electronic nature furnished Michael products with moderate to good enatioselectivity. Some of the very strong acid additives were found to deactivate the carbamate organocatalyst 1 in brine affording poor reaction yield. However, aromatic acid additives, especially 4-nitrobenzoic acid positively impacted Michael reactions in presence of the organocatalyst 1 . The cheap starting materials and easy synthesis of the organocatalyst $\mathbf{1}$ may influence widening of its applications to other $\mathrm{C}-\mathrm{C}$ bond-forming reactions in aqueous media.

\section{Experimental Section}

General. All reagents and starting materials were obtained from commercial sources and used as received. Routine monitoring of reaction was performed by TLC, using precoated silica gel TLC plates obtained by EMerck. All the column chromatographic separations were done by using silica gel (60-120 mesh). Petroleum ether used was of boiling range $60-80^{\circ} \mathrm{C}$. Proton nuclear magnetic resonance (1H NMR) spectra were recorded on $400 \mathrm{MHz}$ Bruker spectrometer. Chemical shifts are expressed in ppm downfield from TMS as internal standard. Infrared (IR) spectroscopy was recorded on a FT-IR spectrometer (Shimadzu). Analytical high performance liquid chromatography (HPLC) was carried out on Agilent instrument using Chiralpak AD-H $(4.6 \mathrm{~mm} \times 250 \mathrm{~mm})$ column at $25{ }^{\circ} \mathrm{C}$ temperature, optical rotations were measured on a B+S ADP-410 digital polarimeter at $\lambda=589 \mathrm{~nm}$.

\section{General experimental procedure}

Procedure for preparation of compound 5. Isobutyl chloroformate $4(0.13 \mathrm{ml}, 1 \mathrm{mmol})$ was added to compound $3(200 \mathrm{mg}, 1 \mathrm{mmol})$ in toluene $(2 \mathrm{ml})$ at room temperature. Triethyl amine $(0.14 \mathrm{ml}, 1 \mathrm{mmol})$ in chloroform $\left(2 \mathrm{ml}\right.$ ) was added to the reaction mixture. The flask was then sealed with $\mathrm{CaCl}_{2}$ guard tube and left stirring for 16 hours at room temperature. Organic layer was then evaporated under vacuum and the product 
was purified by column chromatography. A colourless semi-solid 5 was obtained. Yield $=259 \mathrm{mg}(80 \%) \cdot[\alpha]_{\mathrm{D}}^{20}=$ -30 (c 1.0, $\mathrm{CHCl}_{3}$ ); IR (film, cm $\left.{ }^{-1}\right): 3346,2962,2876,1721,1661,1528 ;{ }^{1} \mathrm{H} \mathrm{NMR}\left(400 \mathrm{MHz}, \mathrm{CDCl}_{3}\right) \delta 0.904(6 \mathrm{H}, \mathrm{d}$, $J=6.4 \mathrm{~Hz}), 1.455(9 \mathrm{H}, \mathrm{s}), 1.713-1.976(5 \mathrm{H}, \mathrm{m}), 3.221-3.436(4 \mathrm{H}, \mathrm{m}), 3.799-3.930(3 \mathrm{H}, \mathrm{m}), 5.873(1 \mathrm{H}, \mathrm{s}) ;{ }^{13} \mathrm{C} \mathrm{NMR}$ $\left(101 \mathrm{MHz}, \mathrm{CDCl}_{3}\right)$ 19.17, 23.23, 23.99, 28.14, 28.57, 29.31, 44.81, 44.07, 44.09, 56.98, 71.07, 79.87, 156, 157.42; $\mathrm{HRMS}(\mathrm{m} / z)$ : calcd for $\mathrm{C}_{15} \mathrm{H}_{28} \mathrm{~N}_{2} \mathrm{O}_{4}[\mathrm{M}+\mathrm{Na}]$ : 323.1947; found: 323.1952 .

Procedure for preparation of compound 1. The BOC protected colourless semi-solid 5 ( $323 \mathrm{mg}, 1 \mathrm{mmol}$ ) was dissolved in a mixture of TFA $(1 \mathrm{ml})$ and DCM $(4 \mathrm{ml})$ and stirred for two hours at room temperature. Then the mixture was basified with concentrated ammonia solution. The organic layer was separated and the aqueous phase was extracted two times by dichloromethane. The combined organic layer was then dried over sodium sulphate and evaporated under vacuum to give a yellowish semi-solid 1. Yield $=191 \mathrm{mg}(95 \%) .[\alpha]_{D}{ }^{20}=-20(c$ 1.0, $\mathrm{CHCl}_{3}$ ); IR (film, cm $\left.{ }^{-1}\right): 3400,2962,2875,2375,1717,1571 ;{ }^{1} \mathrm{H} \mathrm{NMR}\left(400 \mathrm{MHz}, \mathrm{CDCl}_{3}\right) \delta 0.91(6 \mathrm{H}, \mathrm{d}, \mathrm{J}=6.8$ $\mathrm{Hz}), 1.44-1.91(6 \mathrm{H}, \mathrm{m}), 2.98-3.31(4 \mathrm{H}, \mathrm{m}), 3.81(3 \mathrm{H}, \mathrm{m}), 5.50(1 \mathrm{H}, \mathrm{s}) ;{ }^{13} \mathrm{C} \mathrm{NMR}\left(101 \mathrm{MHz}, \mathrm{CDCl}_{3}\right) 19.16,22.81$, 25.68, 28.13, 29.81, 44.77, 58.45, 71.19, 157.38; TOF MS ES $(m / z)$ : calcd for $\mathrm{C}_{10} \mathrm{H}_{20} \mathrm{~N}_{2} \mathrm{O}_{2}[\mathrm{M}+$ ]: 201.1500; found: 201.1300 .

General Procedure for asymmetric Michael addition reaction. To a stirred solution of catalyst 1 in brine, additive was added followed by ketone at room temperature. After 15 minutes of stirring, nitrostyrene was added and the reaction mixture was stirred vigorously at room temperature for 3-6 days and monitored by TLC. The Michael product was then purified by column chromatography using hexane/ethylacetate.

(S)-2-((R)-2-Nitro-1-phenylethyl)cyclohexanone (6). NMR data matched with the previously reported one. ${ }^{59}$ The ee value was determined by the AD-H chiral column. Mobile phase $=n$-Hexane : IPA (90:10), Flow rate $=$ $0.5 \mathrm{ml} / \mathrm{min} ; \lambda=254 \mathrm{~nm} ; t_{\mathrm{R}}$ (minor) $=22.5 \mathrm{~min}, t_{\mathrm{R}}$ (major) $=27.7 \mathrm{~min}$.

(S)-2-((R)-1-(3-Chlorophenyl)-2-nitroethyl)cyclohexanone (7). NMR data matched with the previously reported one. ${ }^{60}$ The ee value was determined by the $\mathrm{AD}-\mathrm{H}$ chiral column. Mobile phase $=n$-Hexane : IPA (90:10), Flow rate $=0.5 \mathrm{ml} / \mathrm{min} ; \lambda=254 \mathrm{~nm} ; t_{\mathrm{R}}$ (minor) $=22.597 \mathrm{~min}, t_{\mathrm{R}}$ (major) $=24.454 \mathrm{~min}$.

(S)-2-((R)-2-Nitro-1-(2-nitrophenyl)ethyl)cyclohexanone (8). NMR data matched with the previously reported one. ${ }^{59}$ The ee value was determined by the AD-H chiral column. Mobile phase $=n$-Hexane : IPA (85:15), Flow rate $=0.5 \mathrm{ml} / \mathrm{min} ; \lambda=254 \mathrm{~nm} ; t_{\mathrm{R}}($ minor $)=16.863 \mathrm{~min}, t_{\mathrm{R}}($ major $)=27.665 \mathrm{~min}$.

(S)-2-((R)-2-Nitro-1-p-tolylethyl)cyclohexanone (9). NMR data matched with the previously reported one. ${ }^{61}$ The ee value was determined by the AD-H chiral column. Mobile phase $=n$-Hexane : IPA (96:4), Flow rate $=0.5$ $\mathrm{ml} / \mathrm{min} ; \lambda=254 \mathrm{~nm} ; t_{\mathrm{R}}($ minor $)=30.049 \mathrm{~min}, t_{\mathrm{R}}($ major $)=39.336 \mathrm{~min}$.

(S)-2-((R)-1-(3-Fluorophenyl)-2-nitroethyl)cyclohexanone (10). NMR data matched with the previously reported one. ${ }^{59}$ The ee value was determined by the $\mathrm{AD}-\mathrm{H}$ chiral column. Mobile phase $=n$-Hexane : IPA (90:10), Flow rate $=0.5 \mathrm{ml} / \mathrm{min} ; \lambda=254 \mathrm{~nm} ; t_{\mathrm{R}}$ (minor) $=22.884 \mathrm{~min}, t_{\mathrm{R}}$ (major) $=25.720 \mathrm{~min}$.

(S)-2-((R)-1-(2-Fluorophenyl)-2-nitroethyl)cyclohexanone (11). NMR data matched with the previously reported one. ${ }^{62}$ The ee value was determined by the $A D-H$ chiral column. Mobile phase $=n$-Hexane : IPA (90:10), Flow rate $=0.5 \mathrm{ml} / \mathrm{min} ; \lambda=254 \mathrm{~nm} ; t_{\mathrm{R}}$ (minor) $=20.263 \mathrm{~min}, t_{\mathrm{R}}$ (major) $=23.941 \mathrm{~min}$.

(S)-2-((R)-1-(2-Chlorophenyl)-2-nitroethyl)cyclohexanone (12). NMR data matched with the previously reported one. ${ }^{59}$ The ee value was determined by the AD-H chiral column.Mobile phase $=n$-Hexane : IPA (95:5), Flow rate $=0.5 \mathrm{ml} / \mathrm{min} ; \lambda=254 \mathrm{~nm} ; t_{\mathrm{R}}($ minor $)=30.121 \mathrm{~min}, t_{\mathrm{R}}($ major $)=52.219 \mathrm{~min}$.

(S)-2-((R)-2-Nitro-1-(4-(trifluoromethyl)phenyl)ethyl)cyclohexanone (13). NMR data matched with the previously reported one. ${ }^{61}$ The ee value was determined by the AD-H chiral column. Mobile phase $=n$-Hexane : IPA (90:10), Flow rate $=0.5 \mathrm{ml} / \mathrm{min} ; \lambda=254 \mathrm{~nm} ; t_{\mathrm{R}}($ minor $)=22.326 \mathrm{~min}, t_{\mathrm{R}}($ major $)=43.176 \mathrm{~min}$. 
(S)-2-((R)-1-(4-Fluorophenyl)-2-nitroethyl)cyclohexanone (14). NMR data matched with the previously reported one. ${ }^{59}$ The ee value was determined by the AD-H chiral column. Mobile phase $=n$-Hexane : IPA (90:10), Flow rate $=0.5 \mathrm{ml} / \mathrm{min} ; \lambda=254 \mathrm{~nm} ; t_{\mathrm{R}}($ minor $)=27.298 \mathrm{~min}, t_{\mathrm{R}}($ major $)=36.514 \mathrm{~min}$.

(S)-2-((R)-2-Nitro-1-(3-nitrophenyl)ethyl)cyclohexanone (15). NMR data matched with the previously reported one. ${ }^{63}$ The ee value was determined by the $A D-H$ chiral column. Mobile phase $=n$-Hexane : IPA (90:10), Flow rate $=1 \mathrm{ml} / \mathrm{min} ; \lambda=254 \mathrm{~nm} ; t_{\mathrm{R}}$ (minor) $=21.653 \mathrm{~min}, t_{\mathrm{R}}$ (major) $=26.482 \mathrm{~min}$.

(S)-2-((R)-2-Nitro-1-phenylethyl)cyclopentanone (16). NMR data matched with the previously reported one. ${ }^{59}$ The ee value was determined by the AD-H chiral column. Mobile phase $=n$-Hexane : IPA (95:5), Flow rate $=1$ $\mathrm{ml} / \mathrm{min} ; \lambda=254 \mathrm{~nm} ; t_{\mathrm{R}}($ minor $)=16.882 \mathrm{~min}, t_{\mathrm{R}}($ major $)=23.388 \mathrm{~min}$.

(R)-5-Nitro-4-phenylpentan-2-one (17)

NMR data matched with the previously reported one. ${ }^{59}$ The ee value was determined by the AD-H chiral column. Mobile phase $=n$-Hexane : IPA (90:10), Flow rate $=0.4 \mathrm{ml} / \mathrm{min} ; \lambda=254 \mathrm{~nm} ; t_{\mathrm{R}}(\operatorname{minor})=27.625 \mathrm{~min}$, $t_{\mathrm{R}}($ major $)=29.624 \mathrm{~min}$.

\section{Acknowledgements}

This work has been supported by Department of Science and Technology, Government of India [Grant No. SR/FT/CS-013/2009]. A.M. is thankful to Department of Science and Technology, Government of India for INSPIRE fellowship.

\section{Supplementary Material}

Copies of ${ }^{1} \mathrm{H},{ }^{13} \mathrm{C}$ NMR spectra, HRMS for compounds 1 and $\mathbf{5}$. Chiral HPLC chromatograms of all the compounds 6-17.

\section{References}

1. Catalytic Asymmetric Synthesis; Ojima, I. Ed.; VCH Publishers: New York, 1993. ISBN: 1560815329

2. Asymmetric Catalysis in Organic Synthesis; Noyori, R. Ed.; John Wiley \& Sons: New York, 1994. ISBN: 0471-57267-5

3. Comprehensive Asymmetric Catalysis; Jacobsen, E. N.; Pflatz, A.; Yamamoto, H., Eds. Springer: Berlin, 1999. ISBN: 978-3-540-64336-4

4. Tomioka, K.; Nagaoka, Y. Chapter 31.1: Conjugate Addition of Oganometallic Reagents. Yamaguchi, M. Chapter 31.2: Conjugate addition of Stabilized Carbanions. In Comprehensive Asymmetric Catalysis; Jacobsen, E. N.; Pfaltz, A.; Yamamoto, H., Eds.; Springer: New York, 1999, Vol. III. ISBN: 978-3-540-64336-4

5. Krause, N.; Hoffmann-Rcder, A. Synthesis 2001, 171-196. http://dx.doi.org/10.1055/s-2001-10803

6. Jha, S. C.; Joshi, N. N. Arkivoc 2002, 167-196. http://dx.doi.org/10.3998/ark.5550190.0003.718

7. Berner, O. M.; Tedeschi, L.; Enders, D. Eur. J. Org. Chem. 2002, 1877-1894. http://dx.doi.org/10.1002/1099-0690(200206)2002:12<1877::AID-EJOC1877>3.0.CO;2-U 
8. Christoffers, J.; Baro, A. Angew. Chem. Int. Ed. 2003, 42, 1688-1690.

http://dx.doi.org/10.1002/anie.200201614

9. Shirakawa, S.; Kobayashi, S. Synlett 2006, 1410-1412.

http://dx.doi.org/10.1055/s-2006-939709

10. Organometallics in Organic Synthesis; Negishi, E. Ed.; Wiley, 1980.

ISBN: 978-0471031932

11. Organic Synthesis Highlights III; Mulzer, J.; Waldmann, H. Eds.; Wiley-VCH, 2008. ISBN: 9783527619962

12. Transition Metals in the Synthesis of Complex Organic Molecules; Hegedus, L. S.; Söderberg, B. C. G.; $3^{\text {rd }}$ Ed., University Science Books, 2009.

ISBN: 978-1891389597

13. Boudier, A.; Bromm, L. O.; Lotz, M.; Knochel, P. Angew. Chem. Int. Ed. 2000, 39, 4414-4435. http://dx.doi.org/10.1002/1521-3773(20001215)39:24<4414::AID-ANIE4414>3.0.CO;2-C

14. Kulinkovich, O. G.; Meijere, A. Chem. Rev. 2000, 100, 2789-2834. http://dx.doi.org/10.1021/cr980046z

15. The Organometallic Chemistry of the Transition Metals; Crabtree, R. H.; $6^{\text {th }}$ Ed., John Wiley \& Sons Inc. 2014.

ISBN: 978-1-118-13807-6

16. Transition Metal Organometallics in Organic Synthesis; Alper, H. Ed.; Academic Press, 2012. ISBN: 9780323161930

17. Howell, G. P. Org. Process, Res. Dev. 2012, 16, 1258-1272. http://dx.doi.org/10.1021/op200381w

18. Heravi, M. M.; Dehghani, M.; Zadsirjan, V. Tetrahedron: Asymmetry 2016, 27, 513-588. http://dx.doi.org/10.1016/i.tetasy.2016.05.004

19. Enantioselective Organocatalysis Reactions and Experimental Procedure; Dalko, P. I. Ed., Wiley-VCH: Weinheim, 2007.

ISBN: 978-3-527-31522-2

20. Koutoulogenis, G.; Kaplaneris, N.; Kokotos, C. G. Beilstein J. Org. Chem. 2016, 12, 462-495. http://dx.doi.org/10.3762/bjoc.12.48

21. Tsakos, M.; Kokotos, C. G. Tetrahedron, 2013, 69, 10199- 10222. https://doi.org/10.1016/i.tet.2013.09.080

22. Bisticha, A.; Triandafillidi, I.; Kokotos, C. G. Tetrahedron: Asymmetry, 2015, 26, 102-108. https://doi.org/10.1016/j.tetasy.2014.12.007

23. Triandafillidi, I.; Bisticha, A.; Voutyritsa, E.; Galiatsatou, G.; Kokotos, C. G. Tetrahedron, 2015, 71, $932-940$. https://doi.org/10.1016/j.tet.2014.12.078

24. Psarra, A.; Kokotos, C. G.; Moutevelis-Minakakis, P. Tetrahedron, 2014, 70, 608-615. https://doi.org/10.1016/i.tet.2013.12.007

25. Revelou, P.; Kokotos, C. G.; Moutevelis-Minakakis, P. Tetrahedron, 2012, 68, 8732-8738. https://doi.org/10.1016/i.tet.2012.08.023

26. Fotaras, S.; Kokotos, C. G.; Kokotos, G. Org. Biomol. Chem., 2012, 10, 5613-5619. https://doi.org/10.1039/c2ob25693b

27. List, B.; Lerner. R. A.; Barbas III C. F. J. Am. Chem. Soc. 2000, 122, 2395-2396. http://dx.doi.org/10.1021/ja994280y 
28. Ahrendt, K.A.; Borths, C.J.; MacMillan, D.W.C. J. Am. Chem. Soc. 2000, 122, 4243-4244. http://dx.doi.org/10.1021/ja000092s

29. Hanessian, S.; Pham, V. Org. Lett. 2000, 2, 2975-2978. http://dx.doi.org/10.1021/ol000170g

30. Dalko, P. I.; Moisan, L. Angew. Chem. Int. Ed. 2001, 40, 3726-3748. http://dx.doi.org/10.1002/1521-3773(20011015)40:20<3726::AID-ANIE3726>3.0.CO;2-D

31. Gröger, H.; Wilken, J.; Berkessel, A. Chapter 18: Simple Amino Acids and Short-Chain Peptides as Efficient Metal-Free Catalysts in Asymmetric Synthesis. In Organic Synthesis Highlights V; Schmalz, H.-G.; Wirth, T. Eds.; Wiley-VCH, 2008; pp 178-186. http://dx.doi.org/10.1002/9783527619986.ch18

32. Dalko, P. I.; Moisan, L. Angew. Chem. Int. Ed. 2004, 43, 5138-5175. http://dx.doi.org/10.1002/anie.200400650

33. Asymmetric Organocatalysis: From Biomimetic Concepts to Applications in Asymmetric Synthesis; Berkessel, A.; Gröger, H. Eds. Wiley-VCH, 2005. ISBN: 978-3-527-30517-9

34. List, B. Chem. Rev. 2007, 107, 5413- 5415. http://dx.doi.org/10.1021/cr078412e

35. MacMillan, D. W. C. Nature 2008, 455, 304-308. http://dx.doi.org/10.1038/nature07367

36. Butler, R. N.; Coyne, A. G. Chem. Rev. 2010, 110, 6302-6337. http://dx.doi.org/10.1021/cr100162c

37. List, B.; Yamamoto, H. Synlett 2011, 461-512. http://dx.doi.org/10.1055/s-002-21715

38. Bhowmick, S.; Bhowmick, K. C. Tetrahedron: Asymmetry 2011, 22, 1945-1979. http://dx.doi.org/10.1016/i.tetasy.2011.11.009

39. Hernández, J. G.; Juaristi, E.; Chem. Commun. 2012, 48, 5396-5409. http://dx.doi.org/10.1039/C2CC30951C

40. Scheffler, U.; Mahrwald, R. Chem. Eur. J. 2013, 19, 14346-14396. http://dx.doi.org/10.1002/chem.201301996

41. Bhowmick, K. C.; Chanda, T. Chapter 12: Asymmetric Organocatalysis in Aqueous Media. In Green Techniques for Organic Synthesis and Medicinal Chemistry ( $2^{\text {nd }}$ Edn); Zhang, W.; Cue, B. W. Eds.; John Wiley \& Sons Ltd.: New Jersey, USA, 2018; pp 291-324. ISBN: 9781119288589.

42. Bhowmick, S.; Kunte, S. S.; Bhowmick, K. C. RSC Adv. 2014, 4, 24311-24315. http://dx.doi.org/10.1039/C4RA02690J

43. Bhowmick, S.; Kunte, S. S.; Bhowmick, K. C. Tetrahedron: Asymmetry 2014, 25, 1292-1297. http://dx.doi.org/10.1016/i.tetasy.2014.07.012

44. Bhowmick, S.; Mondal, A.; Ghosh, A.; Bhowmick, K. C. Tetrahedron: Asymmetry 2015, 26, 1215-1244. http://dx.doi.org/10.1016/j.tetasy.2015.09.009

45. Bhowmick, S.; Kunte, S. S.; Bhowmick, K. C. Indian J. Chem. 2015, 54B, 84-92. http://dx.doi.org/nopr.niscair.res.in/handle/123456789/30315

46. Ghosh, A.; Bhowmick, S.; Mondal, A.; Garai, H.; Bhowmick, K. C. Current Organocatalysis 2016, 3, $133-160$. http://dx.doi.org/10.2174/2213337202666150604232523 
47. Tsakos, M.; Kokotos, C. G.; Kokotos, G. Adv. Synth. Catal., 2012, 354, 740-746. https://doi.org/10.1002/adsc.201100636

48. Tsakos, M.; Kokotos, C. G. Eur. J. Org. Chem., 2012, 576-580. https://doi.org/10.1002/ejoc.201101402

49. Kokotos, C. G.; Kokotos, G. Adv. Synth. Catal., 2009, 351, 1355-1362. https://doi.org/10.1002/adsc.200800812

50. Kaplaneris, N.; Koutoulogenis, G.; Raftopoulou, M.; Kokotos, C. G. J. Org. Chem., 2015, 80, 5464-5473. https://doi.org/10.1021/acs.joc.5b00283

51. Kokotos, C. G.; Limnios, D.; Triggidou, D.; Trifonidou, M.; Kokotos, G. Org. Biom. Chem., 2011, 9, 33863395.

https://doi.org/10.1039/C0OB01083A

52. Rideout, D. C.; Breslow, R. J. Am. Chem. Soc. 1980, 102, 7816-7817.

http://dx.doi.org/10.1021/ja00546a048

53. Mondal, A.; Bhowmick, S.; Ghosh, A.; Chanda, T.; Bhowmick, K. C. Tetrahedron: Asymmetry 2017, 28, 849875. http://dx.doi.org/10.1016/i.tetasy.2017.05.011

54. Mandal, T.; Kuo, W.; Su, M.; Bhowmick, K.; Zhao, J. C. -G. Tetrahedron 2017, 73, 6597-6603. http://dx.doi.org/10.1016/i.tet.2017.10.008

55. Flores-Ferrándiz, J.; Stiven, A.; Sotorríos, L.; Gómez-Bengoa, E.; Chinchilla, R. Tetrahedron: Asymmetry 2015, 26, 970-979.

http://dx.doi.org/10.1016/j.tetasy.2015.07.011

56. Flores-Ferrándiz, J.; Chinchilla, R. Tetrahedron: Asymmetry 2014, 25, 1091-1094. http://dx.doi.org/10.1016/j.tetasy.2014.06.014

57. Flores-Ferrándiz, J.; Chinchilla, R. Tetrahedron: Asymmetry 2017, 28, 302-306. http://dx.doi.org/10.1016/i.tetasy.2016.12.009

58. Hong, L.; Sun, W.; Yang, D.; Li, G.; Wang, R. Chem. Rev. 2016, 116, 4006-4123. http://dx.doi.org/10.1021/acs.chemrev.5b00676

59. Vishnumaya, Singh, V. K. Org. Lett. 2007, 9, 1117-1119. http://dx.doi.org/10.1021/ol070082x

60. Yang, Z.; Liu, J.; Liu, X.; Wang, Z.; Feng, X.; Su, Z.; Hu, C. Adv. Synth. Catal. 2008, 350, 2001-2006. http://dx.doi.org/10.1002/adsc.200800341

61. Saha, S.; Seth, S.; Moorthy, J. N. Tetrahedron Letters 2010, 51, 5281-5286. http://dx.doi.org/10.1016/j.tetlet.2010.07.164

62. Cao, Y-J.; Lai, Y-Y.; Wang, X.; Lia, Y-J.; Xiao, W-J. Tetrahedron Lett. 2007, 48, 21-24. http://dx.doi.org/10.1016/j.tetlet.2006.11.037

63. Zhao, H-W.; Yang, Z.; Yue, Y-Y.; Li, H-L.; Song, X-Q.; Sheng, Z-H.; Meng, W.; Guo, X-Y. Synlett 2014, 25, 293297.

http://dx.doi.org/10.1055/s-0033-1340289 